\title{
Evaluation of Hazardous Waste Management by Using VIKOR: A Case Study of USA States
}

\author{
Mohsin Ali ${ }^{1,2}$, Amit Yadav ${ }^{2}$, Maira Anis ${ }^{2} \&$ Rajeev Kumar Shah ${ }^{2}$ \\ ${ }^{1}$ Department of Environmental Science, Inernational Islamic University, Islamabad, Pakistan \\ ${ }^{2}$ School of Management \& Economics, University of Electronic Science \& Technology of China, Chengdu, China \\ Correspondence: Mohsin Ali, Department of Environmental Science, Inernational Islamic University, Islamabad, \\ Pakistan; School of Management \& Economics, University of Electronic Science \& Technology of China, \\ Chengdu, China. Tel: 0086-18280048212 E-mail: mohsinali757@gmail.com
}

Received: May 27, 2016

doi:10.5539/mas.v11n1p180
Accepted: June 8, 2016

Online Published: November 4, 2016

URL: http://dx.doi.org/10.5539/mas.v11n1p180

\begin{abstract}
Global warming is the major problem of the modern world due to environmental pollution, where hazardous waste disposal poses threat to the environment. USA is urbanized country but still going through hard time due to indecorous management of hazardous waste. To manage such problem are always difficult for the related parties because every individual have their own judgement. Which is difficult to put everyone opinions together for the decision making. The objective of this study was to elucidate hazardous waste problem of USA. This paper espouses VIKOR (VIseKriterijumska Optimizacija I Kompromisno Resenje) methods which is prevalent method applied in multi-criteria analysis (MCA). The empirical studies ranked each state of USA from best to worst for hazardous waste management and will help EPA (environmental protection agency) to improve hazardous waste of each state by comparing with the best.
\end{abstract}

Keywords: hazardous waste, USA, VIKOR, MCA

\section{Introduction}

Hazardous waste is any unsolicited material or solid waste which is disposed in open environment and causes threat to it. It can be in any form such as explosive, emitting radiation, eroding materials, toxic etc. Sources of hazardous waste are timber treatment, petroleum product, metal finished, industrial waste, hospital waste etc. There are numerous ways to extravagance those waste such as neutralization, reduction, oxidation, hydrolysis, microorganisms, incineration, encapsulation and separation etc. It indicates identification and confirmation of the chemical and physical properties of waste, where this is done either by testing or applying knowledge of waste. If such hazardous waste were well managed then there would be clean environment and also not essential to perform any site remediation. Hazardous waste management prominence on hazardous waste storage necessities, above ground storage tanks, underground storage tanks, hazardous waste handling, hazardous waste transportation and disposal. In competitive worlds all countries are rushing towards development and most of the hazardous waste is generated by developed countries such as USA. A waste is considered hazardous when it stances a threat to human health or the environment stated by USA Resource Conservation and Recovery Act (RCRA) of 1978. Speedy improvement and upgrading of various industries machineries, products and practices normally increase the generation rate of hazardous substances.

As stated above most of hazardous waste producers are developed country and same as to USA. From oral view, related parties might find that USA is well managed and free of hazardous waste but the truth is different. Lot of projects in waste were piloted but many of them fail to achieve their goals, bring out social and environmental glitches in the community (Ng et al., 2001; Chui, 2003). Fung (2001) indorsed sustainability idea with the particular authorities and the related parties attempt to progress the design proposal. Competitive world makes rapid improvement of industrial technologies, products and practices frequently additionally alongside also generates hazardous waste. In this research hazardous waste data, information and condition in USA is collected by EPA (environmental protection agency). Evidence is achieved of the chemical and physical properties needed to effectively canned, process or regulatory, stored or disposed of the waste in accordance with authorization. Every state of USA has their own treatment facilities and those facilities have information of the safe and effective treatment of hazardous waste. It seems that it is well managed but the evidence is given by this study 
that still there is lot to improve in the hazardous management. To know the condition of hazardous waste of each states some important variables are taken in consideration for analysis i.e. waste generated, received and managed, shipped offsite, received for transfer storage, population density and number of facilities. In order to ensure that final result is winning over author have used VIKOR method, which is popular method applied in MCA (multi-criteria analysis). The VIKOR (VIseKriterijumska Optimizacija I Kompromisno Resenje) in other word means Multicriteria Optimization and Compromise Solution. The goal of this study is to manage hazardous waste of USA by comparing with the best ranked hazardous waste manage state, giving related officials to take idea from the well managed state and how they follow steps to manage hazardous waste to achieve pollution prevention and human health protection at the source of hazardous waste. Study will also show the condition of hazardous waste, population density and number of facilities in each state.

This paper is organized in 5 sections, where section 1 summaries hazardous waste, section 2 give brief description about the past work on VIKOR and hazardous waste management, section 3 is followed by the methodology for analysis on hazardous waste, section 4 shows elucidation of data analysis and the final section explain the result and give views on improvement of hazardous waste in USA.

As recorded in the Annex III of the waste Framework Directive that waste is classified as being hazardous when it exhibitions one or more of the hazardous properties. The pertinent properties are gritty by property testing, concentration bases criteria. Where on other side, EPA (environmental protection agency) is essential to develop a National Hazardous Waste Management Plan that has esteem to the prevention and minimization of hazardous waste, the gathering and crusade of hazardous waste, the recovery of hazardous waste, disposal cannot be prevented or recovered. There are many facilities such as petroleum investigation, refinish, metal, mining, steel manufacturing etc. which are involved in generation of hazardous waste in USA (Reed et al., 2000). Those waste cause negative effect on the workers' health, land, water, air, flora, fauna and neighborhoods. Some of the major cause of such effect are due to hazardous waste dumped illegally just outside the city, exposure of the neighborhoods and communities to abandoned or close to the waste as well as industrial facilities, major industrial hazardous waste transported to municipal landfills and not securely stored, inadequately treated industrial process waste water causes water pollution etc. (Reed et al., 2000).

Hierarchy for decision making is the best methodology for managing any waste which addresses waste generated, received and managed waste, offsite shipping of hazardous waste, population density and number of facilities in each states of USA. Hazardous waste generation in each state are at various rates but with virtual views or looking at data of hazardous waste production that cannot decide the condition of hazardous waste management. To handle such complex decision making, multi-criteria decision making (MCDM) are worthful for making decision which cannot resolute straightforwardly. A summary equating the features of numerous MCDM methods and dealing with interdependent criteria as well local problems involving both quantitative and qualitative issues are explained by De Montis et al. (2000). Decision makers in multifaceted decision situation involving multi criteria arising from social, economic and environmental consideration helped by MCDA in decision making process (Figueira et al., 2005; Hwang \& Yoon, 2012; Saaty, 1980; Keeney \& Raiffa, 1976). Aiming at solving MCDM problems in which the weights of criteria are unequal using interval- valued fuzzy set concepts the interval-valued fuzzy VIKOR method is used (Vahdani et al., 2010). To solve the MCDM problems with contradictory or non-commensurable criteria the VIKOR method was developed (Opricovic 2009). VIKOR is prevalent method pragmatic in multi-criteria analysis (MCA) but have delinquent in solving MCDM problems. Chang (2010) developed a modified VIKOR method to evade numerical difficulties in resolving glitches by traditional VIKOR method. To confirm the upgrading of solution efficiency, several synthetic experiments were designed. Even the finest solution cannot gratify all criteria when contradictory criteria exist (Opricovic \& Tzeng, 2004; Tong et al., 2007). VIKOR method and a hierarchy MCDM model created on fuzzy sets theory is proposed to deal with the supplier selection problems in the supply chain system (Sanayei et al., 2010). To deal with the evaluation of service quality problems in the international airport, the combined concepts of VIKOR and grey relation analysis (GRA), a new fuzzy MCDM method was proposed (Kuo \& Liang, 2011). Tong et al. (2007) employs the VIKOR method which is a compromising ranking method used for MCDM and to optimize the multi response process.

Though VIKOR is beneficial tool for multiple criteria analysis but there are some glitches for which traditional VIKOR method has no solution (Hsu, 2008). This study used the anticipated VIKOR method for the ranking of USA states according to the condition of hazardous waste. Factors which affect the wizard of hazardous waste such as waste produced, conventional \& managed, dispatched offsite, received for transfer storage, population density and number of facilities in each state are taken for analysis. The objective of this study was to propose a ranking of state according to well managed hazardous waste and the worse managed, then rendering to result 
suggest the worse managed hazardous waste state to follow the well managed procedure for the improvement, illustrate lacking of worse manage state and effect of population on hazardous waste.

\section{Methodology}

The VIKOR method compromise ranking method used for MCDM and to optimize the multi-response process. It was originally developed by Duckstein \& Opricovic (1980) to solve decision problems with contradictory and non-commensurable (different units) criteria, assuming that compromise is acceptable for conflict resolution, the decision maker needs a elucidation that is the closest to the ideal, and the alternatives are evaluated according to all established criteria. VIKOR ranks alternatives and determines the solution named compromise that is the closest to the ideal. The idea of compromise solution was introduced in MCDM by Po-Lung (1973), and Zelrny (1973).

Opricovic (1990) named VIKOR acronym for "VIseKriterijumska Optimizacija I Kompromisno Resenje" that means Multicriteria Optimization and Compromise Solution, with articulation: VIKOR. The real applications were presented in 1998 (Opricovic, 1998). Opricovic \& Tzeng (2004) contributed to the international recognition of the VIKOR method.

The compromise-ranking method VIKOR is an applicable technique for MCA. It was developed for multi-criteria optimization in complex systems. The VIKOR method focuses on ranking and selecting from the alternatives with conflicting criteria (Tzeng et al., 2005). Assuming that each alternative is evaluated according to multiple criterion functions, the compromise ranking is performed by comparing the measure of closeness to the ideal alternative (Opricovic 1998; Tzeng et al., 2002; Opricovic \& Tzeng, 2004). The compromise-ranking algorithm of the traditional VIKOR has following steps.

Step 1: The various alternatives are denoted as $x_{1}, x_{2}, \ldots \ldots, x_{m}$ for an alternative $x_{j}$, the merit of the $\mathrm{i}^{\text {th }}$ aspect is denoted by ${ }^{f_{i j}}$, i.e., $f_{i j}$ is the value of $\mathrm{i}^{\text {th }}$ criteria function for the alternative ${ }^{x}{ }_{j}$. Where, $\mathrm{m}$ is the number of alternative and $\mathrm{n}$ is the number of criteria.

$$
f_{i j}=\frac{x_{i j}}{\sqrt{\sum_{i=1}^{m} X_{i j}^{2}}}, i=1,2, . ., m ; j=1,2, . ., n
$$

Where $x_{i j}=$ performance of alternative $A_{i}$

Step 2: Determine the maximum $f_{i}{ }^{*}$ and minimum $f_{i}^{-}$values of all criteria functions, $i=1,2,3, \ldots \ldots n$.

$$
\begin{aligned}
& f_{i}^{*}=j \max f_{i j}=\max \left[\left(f_{i j}\right) \mid j=1,2, \ldots \ldots, m\right] \\
& f_{i}^{-}=j \min f_{i j}=\min \left[\left(f_{i j}\right) \mid j=1,2, \ldots \ldots, m\right]
\end{aligned}
$$

Step 3: Compute the values $S_{j} \quad \&^{R}{ }_{j}, j=1,2,3, \ldots \ldots \ldots m$.

$$
\begin{gathered}
S_{j}=\sum_{i=1}^{n} w_{i}\left(f_{i}^{*}-f_{i j}\right) /\left(f_{i}{ }^{*}-f_{i}^{-}\right) \\
R_{j}=i \max \left[w_{i}\left(f_{i}^{*}-f_{i j}\right) /\left(f_{i}^{*}-f_{i}^{-}\right) \mid i=1,2, \ldots \ldots n\right]
\end{gathered}
$$

Where $S_{j}$ and ${ }^{R}{ }_{j}$ represents the utility measure and the regret measure, respectively, for the alternative ${ }^{x_{j}}$. $w_{i}$ are the weight of ith criterion, which represents the relative importance of criteria.

Step 4: Compute the values of $Q_{j}, j=1,2, \ldots \ldots m$.

$$
Q_{j}=v\left[\frac{S_{i}-S^{*}}{S^{-}-S^{*}}\right]+(1-v)\left[\frac{R_{i}-R^{*}}{R^{-}-R^{*}}\right]
$$

$$
\begin{aligned}
& S^{*}=j \mathrm{~min} S_{j}=\min \left[\left(S_{j}\right) \mid j=1,2, \ldots \ldots, m\right] \\
& S^{-}=j \max S_{j}=\max \left[\left(S_{j}\right) \mid j=1,2, \ldots \ldots, m\right] \\
& R^{*}=j \min R_{j}=\min \left[\left(R_{j}\right) \mid j=1,2, \ldots \ldots, m\right] \\
& R^{-}=j \max R_{j}=\max \left[\left(R_{j}\right) \mid j=1,2, \ldots \ldots, m\right]
\end{aligned}
$$


Where $\mathrm{v}$ is the weight for the strategy of maximum group utility and 1-v is the weight of the individual regret. ' $\mathrm{v}$ ' is usually set to 0.5 (Kackar, 1985; Opricovic, 1998).

Step 5: Rank the alternatives by $Q_{j}$. The greater the value of $Q_{j}$ is, the better decision of the alternative is. Since it provides a maximum group utility of the "majority" and a minimum individual regret of the opponent", the obtained compromise solution is acceptable by decision makers (Opricovic \& Tzeng, 2007; Tong et al., 2007).

\section{Data Analysis}

The massive majority of hazardous waste in the U.S. is treated or apt off on-site by the generator. For a developed country like U.S. hazardous waste is one of the major problems because as country move towards development, the rate of hazardous waste gears up due to manufacturing products, industrial waste or disposal, chemical use etc. The U.S. Resource Conservation and Recovery Act (RCRA) of 1978 stated that hazardous waste is such waste which causes threat to human health. To prepare sustainable hazardous waste management proposal researchers still have to give an effort to work out the elaborated design based on the resources accessible. Data of hazardous waste had been poised from RTKNet (Right to Know Network) and use of VIKOR made it convenient to discriminate condition of hazardous waste in each state of U.S. To make decision effective and satisfy the majority researcher have taken value of waste generated, received and managed, shipped offsite, received for transfer storage, population density and number of facilities for analysis as shown in Table 1 The basic structure of an MCDM problem established the 50 state of U.S. named 'A' and labeled as 'A1-A50' in Table 2.

Table 1. Hazardous waste data of U.S.

\begin{tabular}{lllllll}
\hline Alternatives & $\begin{array}{l}\text { Waste } \\
\text { Generated } \\
\text { (Tons) }\end{array}$ & $\begin{array}{l}\text { Received } \\
\text { Managed } \\
\text { (Tons) }\end{array}$ & $\begin{array}{l}\text { \& } \\
\text { Offsped } \\
\text { (Tons) }\end{array}$ & $\begin{array}{l}\text { Received } \\
\text { Transfer } \\
\text { Storage }\end{array}$ & $\begin{array}{l}\text { Population } \\
\text { Density } \\
\text { (Million) }\end{array}$ & $\begin{array}{l}\text { Number of } \\
\text { Facilities }\end{array}$ \\
\hline Alaska & 2523 & 12 & 2009 & 5 & 1.2 & 46 \\
California & 561105 & 136700 & 428557 & 46391 & 239.1 & 1269 \\
Colorado & 31900 & 40219 & 34643 & 3621 & 48.5 & 158 \\
Hawaii & 423609 & 139 & 1301 & 51 & 211.8 & 51 \\
Idaho & 3742 & 112054 & 6353 & 184 & 19.0 & 40 \\
Montana & 5883 & 5 & 5956 & 4 & 6.8 & 45 \\
Nevada & 12309 & 76324 & 11928 & 2427 & 24.6 & 102 \\
Oregon & 93525 & 54642 & 77380 & 532 & 39.9 & 181 \\
Utah & 49831 & 135537 & 79516 & 10068 & 33.6 & 113 \\
Washington & 349564 & 15835 & 75735 & 36068 & 9856.5 & 420 \\
Wyoming & 4079 & 5 & 4078 & 6 & 5.8 & 19 \\
Arizona & 202987 & 13051 & 26498 & 4833 & 56.3 & 229 \\
New Mexico & 1037437 & 4227 & 10387 & 510 & 17.0 & 46 \\
Oklahoma & 44783 & 93288 & 29979 & 989 & 54.7 & 203 \\
Texas & 15683408 & 613952 & 607323 & 39663 & 96.3 & 1020 \\
Illinois & 686911 & 369826 & 207880 & 11344 & 231.1 & 1123 \\
Indiana & 888062 & 452403 & 389390 & 10662 & 181.0 & 517 \\
Kansas & 51008 & 267 & 50698 & 303 & 54.5 & 161 \\
lowa & 4399787 & 462718 & 516502 & 23542 & 104.9 & 371 \\
Michigan & 318617 & 422980 & 177234 & 20798 & 174.8 & 490 \\
Minnesota & 354706 & 165633 & 70561 & 3450 & 66.6 & 324 \\
Missouri & 253941 & 149297 & 81411 & 3090 & 87.1 & 343 \\
Nebraska & 35438 & 33716 & 43668 & 3714 & 23.8 & 84 \\
North Dakota & 455867 & 102 & 1178 & 193 & 9.7 & 19 \\
Ohio & 1617571 & 583683 & 565414 & 37391 & 282.3 & 917 \\
South Dakota & 1344 & 2 & 1390 & 102 & 10.7 & 42 \\
Wisconsin & 289401 & 44004 & 173035 & 8848 & 105.0 & 541 \\
Alabama & 588903 & 234002 & 192984 & 12211 & 94.4 & 245 \\
Arkansas & 991143 & 233161 & 206635 & 7436 & 56.0 & 144 \\
Florida & 203410 & 551 & 33514 & 10229 & 350.6 & 451 \\
\hline
\end{tabular}




\begin{tabular}{lllllll}
\hline Georgia & 211462 & 2615 & 42260 & 1247 & 168.4 & 389 \\
Kentucky & 1245285 & 261193 & 135493 & 1056 & 34.9 & 220 \\
Louisiana & 208464 & 89505 & 181969 & 16882 & 109.9 & 274 \\
Mississippi & 1828969 & 17880 & 73084 & 46 & 63.2 & 132 \\
North Caroli & 83317 & 3852 & 90479 & 8424 & 196.1 & 608 \\
South Carol & 177294 & 150184 & 171165 & 4429 & 153.9 & 290 \\
Tennessee & 90138 & 22530 & 52837 & 6324 & 153.9 & 336 \\
Virginia & 74881 & 7 & 71644 & 535 & 202.6 & 391 \\
West Virgin & 62539 & 5940 & 39475 & 486 & 77.1 & 143 \\
Connecticut & 25010 & 6441 & 24073 & 2385 & 738.1 & 297 \\
Delaware & 43287 & 114 & 42972 & 3 & 460.8 & 59 \\
Maine & 2495 & 8 & 2326 & 139 & 43.1 & 66 \\
Maryland & 44254 & 43878 & 54571 & 12584 & 594.8 & 134 \\
Massachusetts & 36915 & 2303 & 42057 & 6614 & 839.4 & 450 \\
New Hampshire & 3950 & 3 & 3950 & 2 & 147.0 & 152 \\
New Jersey & 297706 & 227285 & 328125 & 15113 & 1195.5 & 689 \\
New York & 186486 & 74867 & 165802 & 8542 & 411.2 & 1476 \\
Pennsylvani & 321891 & 384524 & 262670 & 43850 & 283.9 & 853 \\
Rhode Island & 8597 & 4019 & 16222 & 5988 & 1018.1 & 93 \\
Vermont & 2813 & 10 & 2591 & 1506 & 67.9 & 52 \\
\hline
\end{tabular}

In Table 1, there are six criteria known as quantitative criteria which show the value of each criteria and those measure had been taken from RTKNet. Those variables are the main factors which affect hazardous waste management, where population density was derived from formula: total number of people in the state/ total area of the state in $\mathrm{km}$ (kilometers). The data is normalized between 0 and 1 .

Table 2. Ranking of USA States for Hazardous Waste Management

\begin{tabular}{llllllll}
\hline Alternatives & Values S & Sorting S & Values R & Sorting R & Values Q & Sorting Q & Ranking \\
\hline A1 & 0.697482 & 0.306695 & 0.2 & 0.175763 & 0.577889 & 0.074584 & 43 \\
A2 & 0.406362 & 0.386276 & 0.195172 & 0.187954 & 0.200622 & 0.172273 & 4 \\
A3 & 0.662911 & 0.392457 & 0.19904 & 0.19168 & 0.531532 & 0.182202 & 32 \\
A4 & 0.700802 & 0.406362 & 0.199955 & 0.194263 & 0.58179 & 0.200622 & 46 \\
A5 & 0.660227 & 0.439221 & 0.199639 & 0.194295 & 0.530642 & 0.204429 & 31 \\
A6 & 0.696939 & 0.445481 & 0.199999 & 0.194842 & 0.577218 & 0.241664 & 42 \\
A7 & 0.661688 & 0.460728 & 0.199525 & 0.195172 & 0.531981 & 0.253451 & 33 \\
A8 & 0.656496 & 0.473008 & 0.199215 & 0.195334 & 0.524349 & 0.272699 & 28 \\
A9 & 0.61874 & 0.482786 & 0.199342 & 0.196351 & 0.478455 & 0.303706 & 21 \\
A10 & 0.392457 & 0.501663 & 0.194842 & 0.196477 & 0.182202 & 0.305521 & 3 \\
A11 & 0.699521 & 0.550359 & 0.199999 & 0.196901 & 0.580391 & 0.405494 & 45 \\
A12 & 0.667661 & 0.563422 & 0.198882 & 0.196901 & 0.536733 & 0.43809 & 34 \\
A13 & 0.713471 & 0.58739 & 0.199679 & 0.197794 & 0.596252 & 0.438576 & 49 \\
A14 & 0.646961 & 0.593894 & 0.198914 & 0.197894 & 0.51142 & 0.441683 & 25 \\
A15 & 0.550359 & 0.59429 & 0.3 & 0.197896 & 0.799507 & 0.451706 & 50 \\
A16 & 0.439221 & 0.598333 & 0.195334 & 0.197902 & 0.241664 & 0.452108 & 6 \\
A17 & 0.445481 & 0.601722 & 0.196351 & 0.198109 & 0.253451 & 0.453265 & 7 \\
A18 & 0.67924 & 0.608015 & 0.199914 & 0.198257 & 0.555119 & 0.461262 & 37 \\
A19 & 0.482786 & 0.608308 & 0.197896 & 0.19846 & 0.305521 & 0.462577 & 10 \\
A20 & 0.460728 & 0.616022 & 0.196477 & 0.198673 & 0.272699 & 0.472713 & 8 \\
A21 & 0.608015 & 0.61874 & 0.198673 & 0.198691 & 0.462577 & 0.478455 & 19 \\
A22 & 0.608308 & 0.626993 & 0.198257 & 0.198742 & 0.461262 & 0.488228 & 18 \\
A23 & 0.670701 & 0.634595 & 0.199541 & 0.198746 & 0.543125 & 0.500175 & 35 \\
A24 & 0.708161 & 0.635613 & 0.199967 & 0.198882 & 0.590884 & 0.501121 & 48 \\
A25 & 0.306695 & 0.644404 & 0.194295 & 0.198888 & 0.074584 & 0.51142 & 1 \\
A26 & 0.697551 & 0.646961 & 0.2 & 0.198914 & 0.577974 & 0.51242 & 44 \\
A27 & 0.601722 & 0.651087 & 0.197894 & 0.19904 & 0.451706 & 0.522892 & 15 \\
\hline & & & & & & & \\
\hline
\end{tabular}




\begin{tabular}{llllllll}
\hline A28 & 0.563422 & 0.652745 & 0.198109 & 0.199149 & 0.405494 & 0.524349 & 11 \\
A29 & 0.58739 & 0.656496 & 0.198888 & 0.199215 & 0.43809 & 0.525363 & 12 \\
A30 & 0.635613 & 0.658515 & 0.199821 & 0.19925 & 0.501121 & 0.526566 & 24 \\
A31 & 0.658515 & 0.659034 & 0.199149 & 0.199316 & 0.526566 & 0.530642 & 30 \\
A32 & 0.598333 & 0.660227 & 0.199316 & 0.199342 & 0.453265 & 0.531532 & 17 \\
A33 & 0.593894 & 0.661688 & 0.197794 & 0.199525 & 0.441683 & 0.531981 & 14 \\
A34 & 0.707046 & 0.662911 & 0.198742 & 0.199541 & 0.584581 & 0.536733 & 47 \\
A35 & 0.616022 & 0.667661 & 0.198746 & 0.199639 & 0.472713 & 0.543125 & 20 \\
A36 & 0.59429 & 0.670701 & 0.196901 & 0.199679 & 0.438576 & 0.550338 & 13 \\
A37 & 0.644404 & 0.67924 & 0.196901 & 0.199821 & 0.500175 & 0.555119 & 23 \\
A38 & 0.652745 & 0.680111 & 0.199998 & 0.199914 & 0.522892 & 0.558297 & 27 \\
A39 & 0.680111 & 0.681663 & 0.19846 & 0.199955 & 0.550338 & 0.562314 & 36 \\
A40 & 0.651087 & 0.684812 & 0.197902 & 0.199964 & 0.51242 & 0.572276 & 26 \\
A41 & 0.681663 & 0.692924 & 0.199964 & 0.199967 & 0.558297 & 0.574301 & 38 \\
A42 & 0.694569 & 0.694569 & 0.199998 & 0.199997 & 0.574301 & 0.577218 & 41 \\
A43 & 0.634595 & 0.696939 & 0.187954 & 0.199998 & 0.452108 & 0.577889 & 16 \\
A44 & 0.626993 & 0.697482 & 0.19925 & 0.199998 & 0.488228 & 0.577974 & 22 \\
A45 & 0.684812 & 0.697551 & 0.2 & 0.199999 & 0.562314 & 0.580391 & 39 \\
A46 & 0.473008 & 0.699521 & 0.175763 & 0.199999 & 0.204429 & 0.58179 & 5 \\
A47 & 0.501663 & 0.700802 & 0.19168 & 0.2 & 0.303706 & 0.584581 & 9 \\
A48 & 0.386276 & 0.707046 & 0.194263 & 0.2 & 0.172273 & 0.590884 & 2 \\
A49 & 0.659034 & 0.708161 & 0.198691 & 0.2 & 0.525363 & 0.596252 & 29 \\
A50 & 0.692924 & 0.713471 & 0.199997 & 0.3 & 0.572276 & 0.799507 & 40 \\
\hline
\end{tabular}

According to above steps, $S, R$ and $Q$ value had been evaluated as shown in table 2 . Here min value of ' $S$ ', max value of ' $S$ ', min value of ' $R$ ' and max value of ' $R$ ' are shown below:

$S^{*}=$ min value of $\mathrm{S}=0.306, S^{-}=\max$ value of $\mathrm{S}=0.713, R^{*}=$ min value of $\mathrm{R}=0.175, R^{-}=$max value of $\mathrm{R}=$ $0.3 \& \mathrm{~V}=$ weight for the strategy of maximum group utility $=0.5$

Rendering to the Q values, ranking of each state is done with respect to analysis result of hazardous waste management.

\section{Result}

The final result had been shown in Table 2, which revel VIKOR based method for the ranking states of USA according to the ailment of hazardous waste. Result illustrate that Ohio is ranked 1st in the well managed hazardous waste in comparison to other states. Ohio with 282.3 million population density of state with number of facilities 917 for hazardous waste management is ranked 1st but Texas with less population density (96.3 million) and high number of facilities (1020) is ranked 50th. Even having higher number of facilities to manage hazardous waste in comparison to the 1st ranked, Texas ranked last which shows that there is lack of management in hazardous waste. Similarly, Pennsylvania is ranked 2nd with population density of 283.9 million and having 853 number of facilities. In some cases such as Washington has maximum population density (9856.5 million) in comparison to other states with 420 facilities of hazardous waste. Washington is ranked 3rd and it seems that hazardous waste management is sound but still need improvement to get the top ranking. New York is ranked 9th, but it have maximum number of facilities (1476) in comparison to other states and having population of 411.2 million. This shows that even having maximum number of facilities but lack of proper hazardous waste management cannot be accomplished. Similarly in California 2nd highest number of facilities is 1269 with population of 239.1 ranked 4th. California has less population and highest number of facilities in comparison to Ohio (ranked 1st).

\section{Conclusion}

Environmental degradation is major problem in the recent world and a developed country like USA. For enhancing multi-response problems, some methodical processes have been developed in recent years but in this study a systematic technique is used that involves applying the MCDM compromise ranking method VIKOR to optimize what factors are contributing to the hazardous waste of a developed country like USA. The steps followed for the analysis are computing the population density and number of facilities in each state, finding value of VIKOR and optimal condition, carrying out and analyze result of hazardous waste. To optimize the multi-response process the VIKOR index considers the utility and regret measure. 
Overall analysis result shows even having maximum number of facilities with less population or highest population with maximum number of facilities doesn't have substantial hazardous waste management. If there is proper management then even with maximum population with lowest facilities hazardous free environment can be constructed. The result from VIKOR model ranked the states of USA rendering to state of hazardous waste. It is believed that this ranking result will be helpful for the EPA (Environmental Protection Agency) to improve hazardous waste of USA. Result will be also helpful for the EPA and the government in decision making, financial management and their policy making.

\section{References}

Chang, C. L. (2010). A modified VIKOR method for multiple criteria analysis. Environmental monitoring and assessment, 168(1-4), 339-344. http://dx.doi.org/10.1007/s10661-009-1117-0

Chui, E. (2003). Unmasking the "Naturalness" of "Community Eclipse": The case of Hong Kong. Community Development Journal, 38, 151 -163. http://dx.doi.org/10.1093/cdj/38.2.151

De, M. A., De, T. P., Droste-Franke, B., Omann, I., \& Stagl, S. (2000). Criteria for quality assessment of MCDA methods. In: 3rd Biennial Conference of the European Society for Ecological Economics. ESEE, Vienna, 36 May 2000.

Duckstein, L., \& Opricovic, S. (1980). Multiobjective Optimization in River Basin Development. Water Resources Research, 16(1), 14-20. http://dx.doi.org/10.1029/WR016i001p00014

Figueira, J., Greco, S., \& Ehrgott, M. (2005). Multiple Criteria Decision Analysis: State of the Art Surveys. Springer, New York.

Fung, B. C. K. (2001). Planning for high-density development in Hong Kong. Planning Department, Hong Kong.

Hsu, C. H. (2008). The priority strategies on the restraint of land use activities for Tseng-Wen reservoir watershed by using VIKOR method. Department of Environmental Engineering and Science, Chia-Nan University of Pharmacy and Science.

Hwang, C. L., \& Yoon, K. (2012). Multiple attribute decision making: methods and applications a state-of-the-art survey, 186. Springer Science \& Business Media. New York. Springer, Berlin.

Kackar, R. N. (1985). Off-line quality control, parameter design and the Taguchi method. Journal of Quality Technology, 17, 176-188.

Keeney, R. L., \&Raiffa, H. (1976). Decisions with Multiple Objectives: Preferences and Value Tradeoffs. Wiley, New York.

Kuo, M. S., \& Liang, G. S. (2011). Combining VIKOR with GRA techniques to evaluate service quality of airports under fuzzy environment. Expert Systems with Applications, 38(3), 1304-1312. http://dx.doi.org/10.1016/j.eswa.2010.07.003

Opricovic, S. (1990). Programski paket VIKOR za visekriterijumsko kompromisno rangiranje. SYM-OP-IS

Opricovic, S. (1998). Multi-criteria optimization of civil engineering systems. Belgrade: Faculty of Civil Engineering.

Opricovic, S., Tzeng, G. H. (2003). Fuzzy multi-criteria model for post-earthquake land-use planning. Natural Hazards Review, 4(2), 59-64

Opricovic, S., \& Tzeng, G. H. (2004). Compromise solution by MCDM methods: A comparative analysis of VIKOR and TOPSIS. European Journal of Operational Research, 156, 445-455.

Opricovic, S., \& Tzeng, G. H. (2007). Extended VIKOR method in comparison with outranking methods. European Journal of Operational Research, 178, 514-529.

Opricovic, S. (2009). A compromise solution in water resources planning. Water Resour Manage, 23(8),15491561.

Po-Lung, Y. (1973). A Class of Solutions for Group Decision Problems. Management Science, 19(8), 936-946.

Ng, M. K., Cook, A., \& Chui, E. W. T. (2001). The road not travelled: A sustainable urban regeneration strategy for Hong Kong. Planning Practice and Research, 16, $171-183$.

Reed, C., Jacott, M., \& Villamar, A. (2000). Hazardous Waste Management in the United States-Mexico Border States: More Questions than Answers. Red Mexicana de Acción Frente al Libre Comercio (RMALC), La 
Neta - Proyecto Emisiones: Espacio Virtual, Mexico City, D.F. Mexico and Texas Center for Policy Studies, Austin, Texas (2nd Ed.).

Saaty, T. L. (1980). Analytic Hierarchy Process. McGraw Hill, New York.

Sanayei. A., Mousavi. S. F., \& Yazdankhah, A. (2010). Group decision making process for supplier selection with VIKOR under fuzzy environment. Expert Systems with Applications, 37(1), 24-30

Tong, L. I., Chen, C. C., \& Wang, C. H. (2007). Optimization of multi-response processes using the VIKOR method. The International Journal of Advanced Manufacturing Technology, 31(11-12), 1049-1057.

Tzeng, G. H., Lin, C. W., \& Opricovic, S. (2005). Multi-criteria analysis of alternative-fuel buses for public transportation. Energy Policy, 33, 1373-1383.

Tzeng, G. H., Teng, M. H., Chen, J. J., \& Opricovic, S. (2002).Multicriteria selection for a restaurant location in Taipei. International Journal of Hospitality Management, 21(2), 171-187.

Vahdani, B., Hadipour, H., Sadaghiani, J. S., \& Amiri, M. (2010). Extension of VIKOR method based on interval-valued fuzzy sets. The International Journal of Advanced Manufacturing Technology, 47(9-12), 1231-1239. http://dx.doi.org/10.1007/s00170-009-2241-2

Zelrny, M. (1973). Compromise Programming. In J. L. Cochrane \& M. Zeleny (Eds.), Multiple Criteria Decision Making, University of South Carolina Press, Columbia.

\section{Copyrights}

Copyright for this article is retained by the author(s), with first publication rights granted to the journal.

This is an open-access article distributed under the terms and conditions of the Creative Commons Attribution license (http://creativecommons.org/licenses/by/4.0/). 